\title{
Estresse hídrico e salino na germinação de sementes de feijão-caupi cv. BRS Pajeú
}

Aroldo Gomes Filho, Elisane Nascimento Rodrigues, Thales Castro Rodrigues, Valdomiro Júnior Neres Santos, Sérgio Ferreira Alcântara, Fabiana Neres de Souza

Instituto Federal Norte de Minas Gerais, IFNMG, Campus Januária, MG. E-mail: aroldo.gomes@ifnmg.edu.br

\section{Resumo}

O presente trabalho objetivou analisar o desempenho fisiológico de sementes de feijão-caupi cv. BRS Pajeú submetidas à diferentes potenciais e agentes osmóticos, permitindo o conhecimento sobre como o estresse influencia na germinação e vigor destas sementes. O experimento foi conduzido no delineamento inteiramente casualizado, com os tratamentos em arranjo fatorial sendo dois agentes osmóticos e cinco potenciais osmóticos $(2 \times 5)$, com quatro repetições. Os resultados obtidos foram submetidos à análise de variância, e quando constatados efeitos significativos, foram submetidos à análise de regressão. As condições de estresse salino prejudicaram a germinação e o vigor das sementes de feijão-caupi cv. BRS Pajeú. A diminuição do potencial osmótico das soluções, reduz o desenvolvimento e o ganho de massa fresca e seca das plântulas de feijão-caupi cv. BRS Pajeú, independente da substância utilizada para indução do estresse. $\mathrm{O}$ cloreto de sódio $(\mathrm{NaCl})$ promoveu efeitos mais drásticos sobre o crescimento das plântulas, quando comparado ao cloreto de potássio $(\mathrm{KCl})$. As sementes de feijão-caupi cv BRS Pajeú submetidas à solução de $\mathrm{NaCl}$ com potenciais osmóticos inferiores a $-0,35 \mathrm{MPa}$, apresentou porcentagem inferior a $80 \%$ de germinação.

Palavras-chave: Vigna unguiculata (L).; salinidade; vigor.

\section{Salt and water stress on seed germination of cowpea cv. BRS Pajeú}

\begin{abstract}
The aim of this work was to evaluate the germination physiological of cowpea seed cv. BRS Pajeú submitted to different potentials and osmotic agents, allowing the knowledge about how the stress effects the germination and vigor of these seeds. The experiment was conducted in a completely randomized design, with treatments in five different potentials and two osmotic agents $(2 \times 5)$ factorial arrangement, with four replications. The results were submitted to variance analysis, and when significant effects were verified, they were submitted to regression analysis. The saline stress conditions impaired germination and vigor of cowpea seeds. The decrease in the osmotic potential of the solutions reduces the development and fresh and dry mass gain of cowpea cv. BRS Pajeú, independent of the substance used for stress induction. Sodium chloride $(\mathrm{NaCl})$ promoted more drastic effects on seedling growth when compared to potassium chloride $(\mathrm{KCl})$. The cowpea seeds submitted to $\mathrm{NaCl}$ solution with potentials inferior to $-0.35 \mathrm{MPa}$, presented less than $80 \%$ of germination.
\end{abstract}

Keywords: Vigna unguiculata (L).; salinity; vigor.

\section{Introdução}

O feijão-caupi [Vigna unguiculata (L.) Walp. (Fabaceae)], é comumente conhecido como feijão-de-corda, feijão catador e feijãogurutuba em algumas regiões do Norte de Minas Gerais. Esta cultura é geralmente produzida para o consumo de grãos verdes ou maduros, além disso, vem sendo bastante utilizada para a adubação verde, pois, a cultura é rica em nutrientes (VALE et al., 2017).

O feijão-caupi ocupa a maior área semeada com feijão na segunda safra de $2018 / 2019$ no país, com 880,6 mil hectares e produção estimada de 437,0 mil toneladas 
(CONAB, 2019). A expansão da cultura tem ocorrido principalmente para as regiões de cerrado, devido à precocidade e a tolerância ao déficit hídrico em relação a outras culturas, além de possuir porte ereto, adaptação ao cultivo mecanizado, baixo custo e a possibilidade de bons rendimentos vem sendo os principais atrativos para o cultivo desta leguminosa (BASTOS et al., 2016).

Com essa grande expansão da produção que a cultura vem ganhando, é de extrema importância a obtenção de sementes que apresentem uma boa qualidade fisiológica. Ao qual duas características são fundamentais avaliar a qualidade fisiológica destas sementes, a viabilidade e o vigor (MARCOS FILHO, 2005). A viabilidade é determinada pelo teste de germinação. Enquanto, o vigor compreende um conjunto de características que determinam o potencial fisiológico das sementes (VIEIRA; CARVALHO, 1994).

De acordo com Carvalho e Nakagawa (2012), para que as sementes apresentem uma boa germinação são necessárias condições favoráveis de luz, temperatura e disponibilidade de água. Porém, nem sempre essas condições são adequadas. $O$ feijão-caupi é cultivado, predominantemente, em regiões áridas propícias a condições de déficit hídrico e solos que apresentam baixa fertilidade (SOUZA et al., 2016).

Nas regiões semiáridas, é comum a presença de solos com níveis elevados de sais. Um dos principais fatores desta condição está relacionado com o avanço do intemperismo químico de minerais primários, onde sais solúveis como cloretos, sulfatos e bicarbonatos de $\mathrm{Na}, \mathrm{Ca}$, e $\mathrm{Mg}$, ou ainda em menores quantidades $\mathrm{K}^{+}$, $\mathrm{NH}_{4}{ }^{+}, \mathrm{NO}_{3}{ }^{+}$e $\mathrm{CO}_{3}{ }^{2-}$, se concentram nos horizontes ou camadas do perfil do solo. Além disso, as baixas taxas pluviométricas e elevada evaporação da água no solo, contribuem para o acúmulo de sais em sua superfície, sendo potencializado em áreas irrigadas onde não há previsão de drenagem, lâmina insuficiente de água de irrigação, uso de água salina ou ainda, a combinação destes fatores (RIBEIRO et al., 2016).

A presença de altas concentrações de íons na solução é proporcional à redução do potencial hídrico, no qual a água fica osmoticamente retida na solução salina, tornando-se cada vez menos disponível conforme ao aumento da concentração destes sais, o que influencia negativamente na absorção de água pela semente, e consequentemente afeta o potencial germinativo e o desenvolvimento das plântulas (RIBEIRO et al., 2001).

Sob condições de déficit hídrico, um dos efeitos primários desencadeados nas plantas é a desidratação celular, que consequentemente provocam redução no potencial de pressão (turgor) e no volume celular. Tal condição desencadeia efeitos secundários, como o acúmulo da concentração de íons no citosol, tornando-se citotóxicos pois causam desnaturação de proteínas e desestabilização das membranas, podendo culminar na morte celular (TAIZ et al., 2017). Em sementes, os principais efeitos observados na literatura são: redução da percentagem de germinação, redução da raiz primária e do hipocótilo e aumento do tempo médio para germinação (DEMONTIÊZO et al., 2016; FREIRE et al., 2018; LARRÉ et al., 2014; RABANI et al., 2013).

As limitações na germinação das sementes causadas por déficit hídrico afetam o estabelecimento da cultura, pois cada espécie possui um valor de potencial hídrico externo abaixo do qual afetará negativamente a germinação da semente (PEREIRA et al., 2012). Durante os estágios de crescimento e reprodutivo, alguns dos principais efeitos secundários do estresse hídrico e salino nas plantas, englobam o fechamento estomático, redução das atividades celulares e metabólicas e inibição fotossintética (TAIZ et al., 2017), afetando negativamente na produção de fotoassimilados, e consequentemente na produtividade econômica.

Um dos mecanismos adaptativos citados na literatura para a manutenção da turgescência e do crescimento sob baixos potenciais hídricos, é o ajustamento osmótico que pode ser alcançado pelo acúmulo de solutos orgânicos como prolina e açúcares solúveis (SILVEIRA et al., 2009). Souza et al. (2011) relatam que para o feijão-caupi, os principais mecanismos de tolerância à salinidade, se baseiam na exclusão foliar do íon $\mathrm{Na}^{+}$, retendo-o no sistema radicular nos primeiros dias de exposição ao estresse salino, bem como à manutenção da disponibilidade de carboidratos solúveis, mesmo quando submetidos a altas concentrações de $\mathrm{NaCl}$.

Neste sentido, o presente trabalho foi desenvolvido com o objetivo de avaliar o efeito do estresse salino na germinação e no vigor de sementes de feijão-caupi cv. BRS Pajeú. 


\section{Material e Métodos}

O experimento foi conduzido no Laboratório de Fisiologia Vegetal do Instituto Federal do Norte de Minas Gerais do campus Januária no período de 20 a 28 de junho de 2018, utilizando 0 delineamento inteiramente casualizado em arranjo fatorial $2 \times 5$ (agentes osmóticos $\times$ potenciais osmóticos) com quatro repetições. Foram utilizadas sementes de feijãocaupi Vigna unguiculata (L.) cv. BRS Pajeú provenientes de experimentos anteriores durante a safra 2014, sendo estas armazenadas em embalagens hermeticamente fechadas sob refrigeração à uma temperatura de $5^{\circ} \mathrm{C}$ e umidade relativa de $55 \%$.

As sementes foram submetidas à germinação sendo estudado o efeito de dois agentes osmóticos $\mathrm{NaCl}$ e $\mathrm{KCl}$, para simulação de estresse hídrico e salino, respectivamente, em cinco níveis de potenciais osmóticos: 0 (água destilada), -0,20, -0,40, -0,60, $-0,80 \mathrm{MPa}$, calculados pela fórmula de Van't Hoff (BRAGA et al., 1999). As sementes foram inicialmente esterilizadas em hipoclorito de sódio (2\%) por um minuto, e, posteriormente, semeadas, obedecendo a um espaçamento equidistante, sobre três folhas de papel Germitest, sendo duas como base e uma para cobrir, umedecidas com o equivalente a 2,5 vezes a massa do papel seco com as soluções descritas anteriormente (tabela 1).

Tabela 1. Quantidade de soluto utilizada para preparação de soluções de diferentes potenciais osmóticos com cloreto de potássio $(\mathrm{KCl})$ e de sódio $(\mathrm{NaCl})$, em temperatura de $25^{\circ} \mathrm{C}$

\begin{tabular}{lll}
\hline $\begin{array}{l}\text { Potencial osmótico } \\
(\mathrm{MPa})\end{array}$ & $\mathrm{KCl}$ & $\mathrm{NaCl}$ \\
\cline { 2 - 3 } & $\mathrm{g} \mathrm{L}^{-1}$ de água destilada & \\
\hline$-0,20$ & & \\
$-0,40$ & 0,331 & 4,730 \\
$-0,60$ & 0,662 & 9,460 \\
$-0,80$ & 0,993 & 14,190 \\
& 1,324 & 18,920
\end{tabular}

Em seguida, os papéis foram enrolados e embalados em sacos plásticos transparentes, os quais foram vedados a fim de reduzir a perda de umidade. O teste de germinação foi conduzido com quatro sub-amostras de 50 sementes para cada tratamento, de acordo com os critérios estabelecidos nas Regras para Análise de Sementes (BRASIL, 2009). Os rolos confeccionados, foram acondicionados em câmara germinadora do tipo B.O.D. (LT 320 TFPII), regulada para manter temperatura constante de $25 \pm 2{ }^{\circ} \mathrm{C}$.
A avaliação da primeira contagem de germinação foi realizada no quinto dia após a instalação do teste. A contagem final de germinação (segunda contagem), obtida pela somatória com a primeira contagem de germinação, foi realizada no oitavo dia após a instalação do teste (BRASIL, 2009). Para o teste de vigor, foi feito a seleção das plântulas normais obtidas do teste de germinação, seguindo os critérios estabelecidos nas Regras para Análise de Sementes (BRASIL, 2009) exposta na Figura 1. 
Figura 1. Plântulas classificadas como normais.

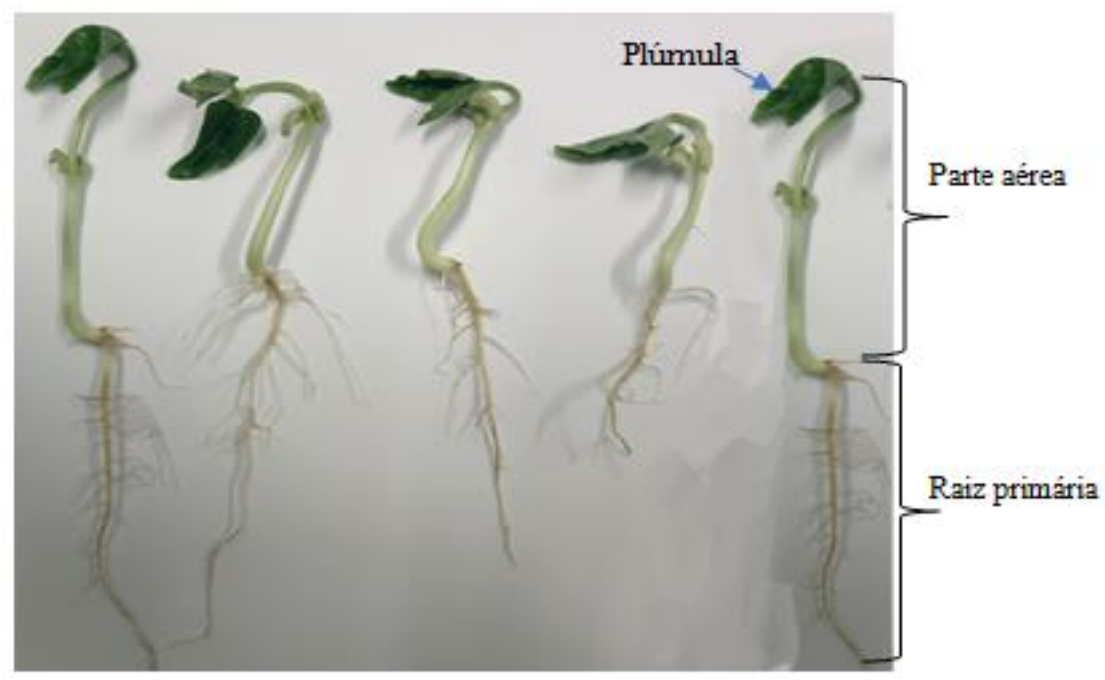

O comprimento da parte aérea e da raiz primária das plântulas foi determinado com auxílio de um paquímetro digital, medindo-se toda a estrutura da parte aérea desde a inserção da plúmula até a inserção da raiz e o comprimento médio da raiz foi medido toda a estrutura da raiz primária. A determinação da massa fresca de plântula foi realizada após a avaliação do comprimento da raiz e da parte aérea. Nesta avaliação, foram consideradas todas as plântulas normais originadas nos respectivos tratamentos, as quais foram pesadas em balança de precisão $(0,01 \mathrm{~g})$. A massa total obtida, em cada amostra, foi dividida pelo número de plântulas normais utilizadas, obtendo-se a biomassa fresca média de plântula (g plântula ${ }^{-1}$ ).

Após a pesagem, as plântulas normais foram acondicionadas em sacos de papel e levadas para secar em estufa com circulação forçada de ar, regulada à temperatura de $65^{\circ} \mathrm{C}$, por um período de $72 \mathrm{~h}$. Em seguida, foi realizada a pesagem do material, obtendo-se a massa seca com precisão de 0,01 g. A massa total obtida, em cada amostra, foi dividida pelo número de plântulas normais utilizadas, obtendo-se a biomassa seca média de plântula (g plântula ${ }^{-1}$ ).

Os resultados obtidos foram submetidos à análise de variância, e quando constatados efeitos significativos $(P<0,05)$, foram submetidos à análise de regressão $(P<0,05)$, sendo os modelos selecionados com base na significância dos parâmetros e com a melhor explicação fisiológica dos fenômenos, com isso, os modelos de regressão linear de primeiro grau e exponencial foram os que melhor se ajustaram aos dados. As análises estatísticas foram realizadas com o auxílio do software estatístico GENES (CRUZ, 2016).

\section{RESULTADOS E DISCUSSÕES}

Os resultados apresentados na análise de variância (Tabela 2) indicam diferenças significativas em todas as variáveis estudadas $(P<0,05)$, com exceção para a variável massa fresca na interação (potenciais $\times$ agentes), $(P<0,01)$. 
Tabela 2. Análise de variância para as variáveis comprimento de parte aérea (CPA), comprimento de raiz (CRAIZ), relação parte aérea/raiz (RPAR), massa fresca (MF), massa seca (MS) e germinação (G\%) em feijãocaupi variedade BRS Pajeú em teste realizado em Januária-MG.

\begin{tabular}{|c|c|c|c|c|c|c|c|}
\hline \multirow{2}{*}{ FV } & \multirow{2}{*}{$\mathrm{GL}$} & \multicolumn{6}{|c|}{ QM } \\
\hline & & CPA & CRAIZ & RPAR & $\mathrm{MF}$ & MS & G\% \\
\hline POTENCIAIS & 3 & $4533,51^{* *}$ & $20163,72^{* *}$ & $0,35^{* *}$ & $1294,21^{* *}$ & $9,17^{* *}$ & $3045,025^{* *}$ \\
\hline AGENTES & 1 & $5216,65^{* *}$ & $25204.66^{* *}$ & $0,67^{* *}$ & $1188,79^{* *}$ & $9,76^{* *}$ & $885,31^{* *}$ \\
\hline РОT X AGE & 1 & $543,31^{* *}$ & $2126,25^{* *}$ & $0,20^{* *}$ & $113,11^{*}$ & $1,06^{* *}$ & $516,83^{* *}$ \\
\hline RESÍDUO & 27 & 60,17 & 143,51 & 0,02 & 30,02 & 0,10 & 33,33 \\
\hline CV\% & & 20,87 & 20,68 & 23,99 & 33,92 & 22,71 & 6,69 \\
\hline MÉDIA & & 32,60 & 55,13 & 0,46 & 14,25 & 1,29 & 85,11 \\
\hline
\end{tabular}

$\mathrm{Na}$ Figura 2 são apresentados os resultados que se ajustaram ao modelo linear de primeiro grau para os valores de comprimento da parte aérea das plântulas de feijão-caupi submetidas às soluções de $\mathrm{NaCl}$ e $\mathrm{KCl}$. As plântulas que foram submetidas ao potencial $0,00 \mathrm{MPa}$ (testemunha) no tratamento com $\mathrm{NaCl}$ apresentaram valores de comprimento da parte aérea de aproximadamente $66 \mathrm{~mm}$. Quando as mesmas foram submetidas ao potencial $-0,20$ $\mathrm{MPa}$, apresentaram um comprimento de 45,86 $\mathrm{mm}$, acarretando assim, uma perda de $29,66 \%$ do CPA, e quando foram submetidas ao potencial $0,40 \mathrm{MPa}$ apresentaram um comprimento de $26,52 \mathrm{~mm}$, obtendo uma redução de $59,62 \%$ do CPA, ressaltando, contudo, que essas reduções são em comparação com a plântulas submetidas ao potencial 0,00 MPa (testemunha). As plântulas apresentaram desenvolvimento no tratamento com $\mathrm{NaCl}$, em potenciais superiores à $-0,67 \mathrm{MPa}$ e as plântulas submetidas ao tratamento com $\mathrm{KCl}$, em potenciais superiores à $-1,25 \mathrm{MPa}$, ou seja, em potenciais inferiores a esses valores as plântulas de feijão-caupi cv. BRS Pajeú não apresentaram comprimento da parte aérea, segundo a análise de regressão. Verifica-se que, as plântulas apresentaram-se mais sensíveis ao $\mathrm{NaCl}$ em relação ao $\mathrm{KCl}$, e que quanto mais negativo foi o potencial osmótico, menores foram os valores do comprimento da parte aérea. 
Figura 2. Comprimento da parte aérea em plântulas de feijão-caupi, cv. BRS-Pajeú, submetidas à níveis de potencial osmótico em cloreto de sódio ( $\mathrm{NaCl}$ ) e cloreto de potássio $(\mathrm{KCl})$. Januária, MG, 2018.

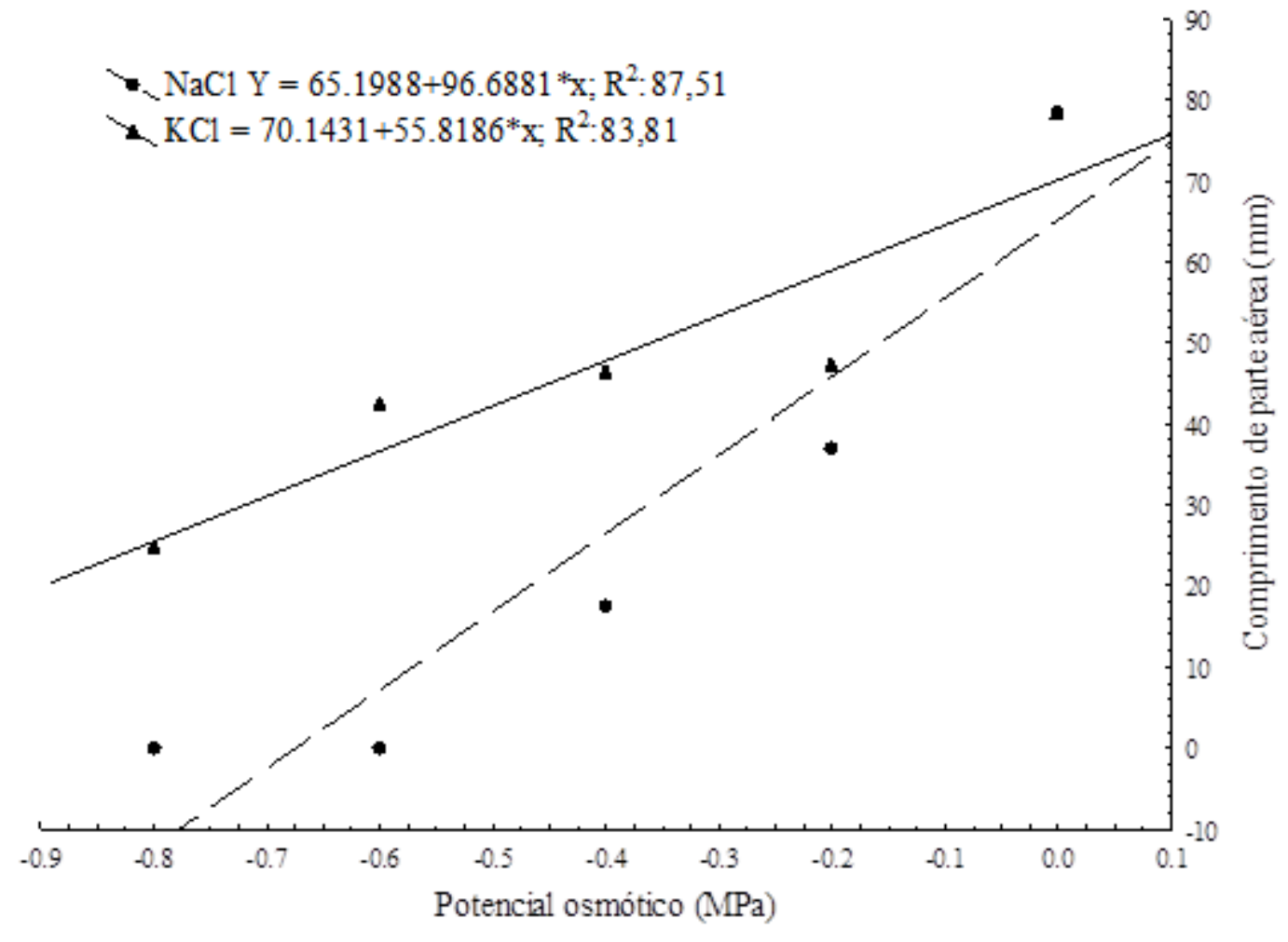

Esse mesmo comportamento foi observado por Coelho et al. (2013), que, trabalhando com a cultivar pele de moça do feijão vigna, relataram que em concentrações mais elevadas, ou seja, potenciais mais negativos, o estresse salino provoca redução na altura, número de folhas e biomassa seca da parte aérea das plantas. Segundo Bewley e Black (1994), esse comportamento da redução no comprimento das plântulas se deve às mudanças na turgescência celular em função da diminuição da síntese de proteína nas condições de estresse hídrico. No entanto, a redução do potencial hídrico e os efeitos tóxicos dos sais interferem inicialmente no processo de absorção de água pelas sementes, influenciando a germinação e o desenvolvimento das plântulas (SOUSA et al., 2009).

Para o comprimento de raiz (Figura 3), o modelo linear de primeiro grau foi o que melhor se ajustou para plântulas originadas das sementes submetidas ao cloreto de sódio $(\mathrm{NaCl})$. Na representação gráfica, observa-se claramente que, à medida que diminui o potencial osmótico da solução no substrato, o comprimento da raiz primária decresce, assim, plântulas submetidas a potenciais inferiores a 0,71 $\mathrm{MPa}$, não apresentaram desenvolvimento da raiz primária. 
Figura 3. Comprimento de raiz em plântulas de feijão-caupi, cv. BRS-Pajeú, submetidas a níveis de potencial osmótico em cloreto de sódio ( $\mathrm{NaCl}$ ) e cloreto de potássio (KCl). Januária, MG, 2018.

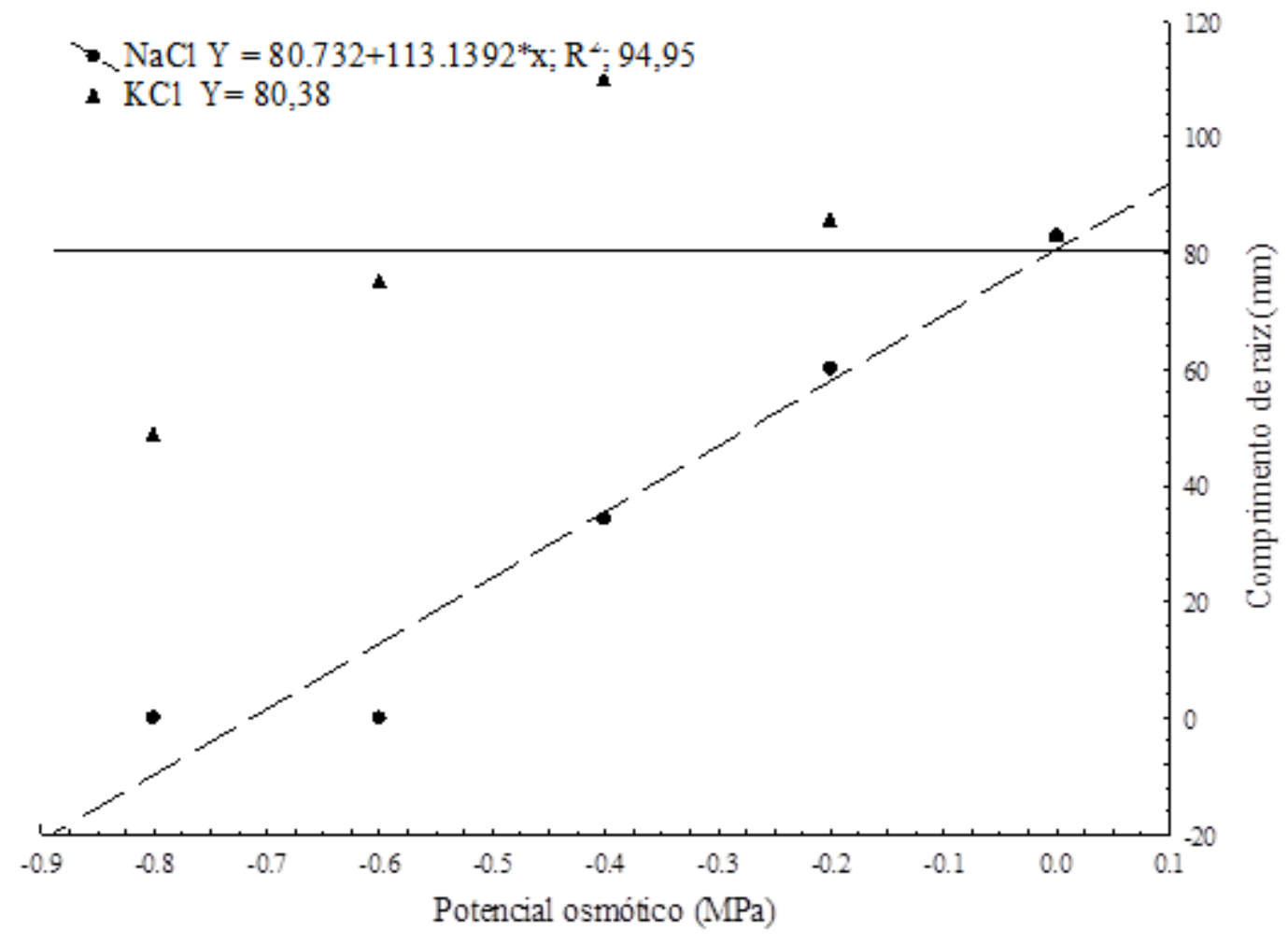

Segundo Almeida et al. (2011) a presença de sais na zona radicular da planta provoca redução da permeabilidade do sistema radicular à água, induzindo ao déficit hídrico que, por consequência, leva à redução na taxa de fotossíntese e na taxa de crescimento, fato que pode ter ocorrido nas plântulas de feijão-caupi cv. BRS Pajeú. Essa redução também foi observada por Dalchiavon et al. (2016), em estudos sobre o efeito de estresse salino em sementes de feijão comum, ao qual, os autores relataram que o aumento da concentração salina ocasionou redução no crescimento das raízes, impedindo seu normal desenvolvimento.

Dal'Masso et al. (2013), trabalhando com sementes de Chia (Salvia hispânica) observou que, na medida em que aumentou a concentração das soluções, ou seja, potenciais mais negativos, ocorreu uma tendência de menor crescimento tanto das plântulas como da raiz. Fato também observado por Moterle et al. (2006), através da redução no comprimento da raiz primária de plântulas de milho de pipoca, conforme o potencial osmótico foi diminuindo. Os resultados de comprimento da raiz primária para às plântulas submetidas a solução de $\mathrm{KCl}$, não se ajustaram a nenhum dos modelos estatísticos de regressão, ao qual a média para comprimento de raiz foi de $80,38 \mathrm{~mm}$.

$\mathrm{Na}$ figura 4, verifica-se que a relação parte aérea/raiz de ambas as soluções proporcionaram respostas semelhantes, tendo efeito linear decrescente com o aumento das concentrações, o mesmo comportamento foi observado por Paiva (2014), trabalhando com plântulas de feijão-caupi, verificou que o comprimento de raiz e parte aérea foram afetadas a medida que houve aumento nos níveis de salinidade, o autor explica que a salinidade reduz o crescimento radicular em função do aumento do potencial osmótico do solo, dessa forma, há a redução da permeabilidade no solo, promovendo a redução do porte da planta. Além desses fatores, o acúmulo de sais no tecido vegetal inibe os processos fisiológicos e metabólicos na planta. Resultados que, também, estão de acordo com Dickmann et al. (2005), trabalhando com sementes de girassol, concluíram que em potenciais osmóticos mais negativos produzem decréscimo no vigor de sementes, podendo ser avaliado pelo comprimento de plântula. 
Figura 4. Relação parte aérea/Raiz de plântulas de feijão-caupi, cv. BRS-Pajeú, submetidas a diferentes níveis de potencial osmótico em cloreto de sódio $(\mathrm{NaCl})$ e cloreto de potássio $(\mathrm{KCl})$. Januária, $\mathrm{MG}, 2018$.

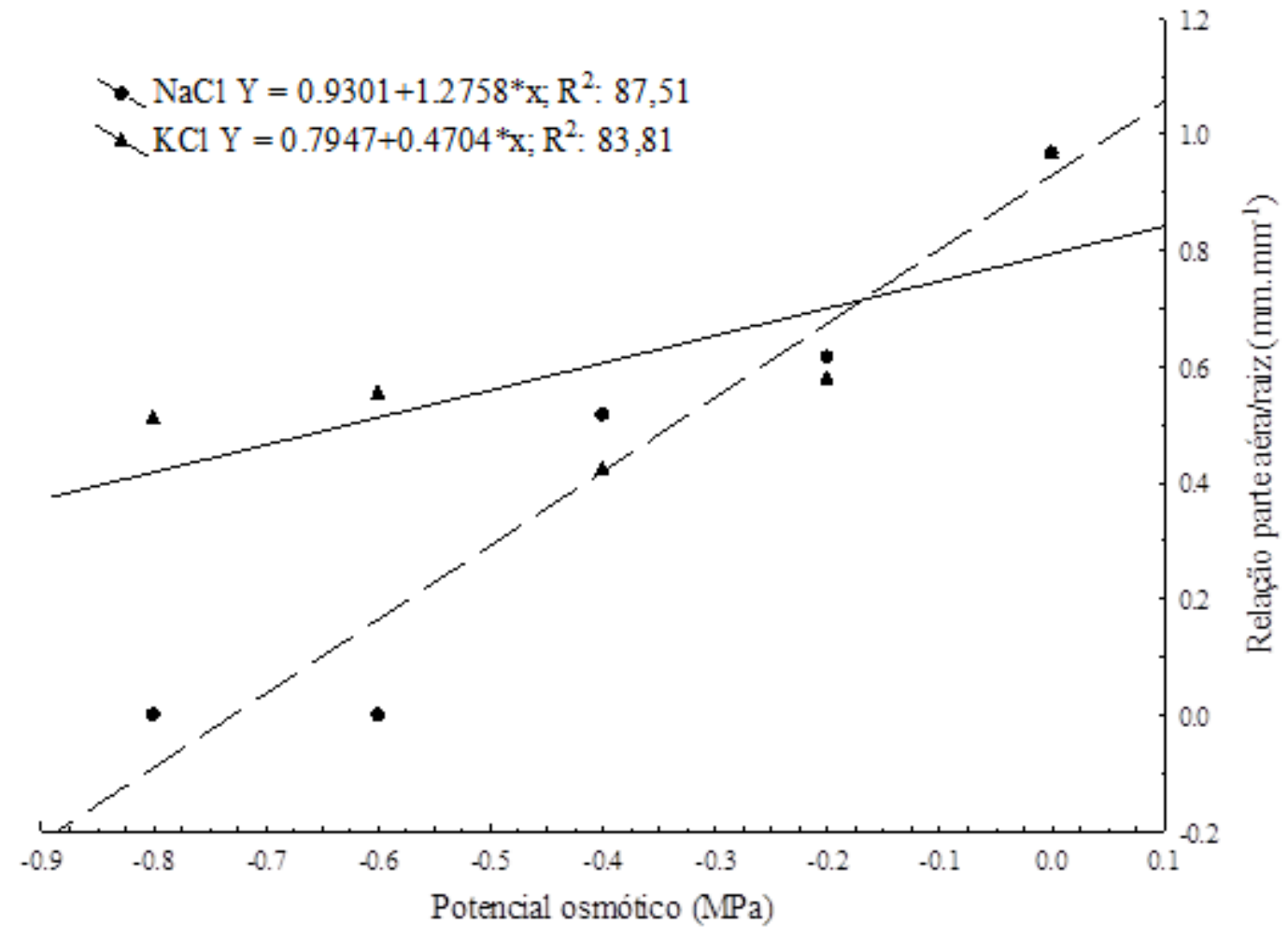

De acordo com os resultados, observouse que há maior perda da parte aérea das plântulas em relação à raiz primaria. Santos et al. (2009), verificaram que a maior perda da parte aérea em relação a raiz primaria em cultivares de feijoeiro, pode estar relacionada à resposta do sistema radicular, visando ampliar o volume no solo, e o explorar como forma de amenizar os efeitos prejudiciais da salinidade na aquisição de água e nutrientes, ou seja induz a maior perda da parte aérea em relação a raiz primaria para as plântulas de feijão-caupi cv. BRS Pajeú.

Os resultados apresentados demonstram que o $\mathrm{NaCl}$ se mostrou mais nocivo em relação ao $\mathrm{KCl}$, pois houve um menor estresse nas plantas quando submetidas ao tratamento com $\mathrm{KCl}$. As plântulas sob cloreto de sódio apresentaram menores valores para relação parte aérea/raiz quando exposta aos potenciais superiores à $-0,72$ $\mathrm{MPa}$, e com relação ao tratamento com cloreto de potássio, obteve-se valores inferiores de relação parte aérea/raiz quando as plantas foram submetidas aos potenciais superiores à $-1,78$ $\mathrm{MPa}$, apresentando, assim, uma grande diferença quanto a tolerância a potenciais mais negativos entre os dois agentes.

As Figuras 5 e 6 apresentaram um comportamento semelhante para massa fresca e seca das plântulas quando submetidas aos diferentes níveis de potencial osmótico dos agentes $\mathrm{NaCl}$ e $\mathrm{KCl}$. As sementes submetidas à solução com $\mathrm{NaCl}$, demostraram que, em potenciais menores a $-0,4 \mathrm{MPa}$, tiveram perda de $73 \%$ do ganho de massa fresca, e $67 \%$ de perda no ganho de massa seca, quando comparados a testemunha, isso demostra que potenciais menores que $-0,4$ não apresentaram valores significativos ao ganho de massa seca e fresca da plântula, este mesmo comportamento foi observado para as plântulas submetidas à solução com $\mathrm{KCl}$. 
Figura 5. Massa de matéria fresca de plântulas de feijão-caupi, Cv. BRS-Pajeú, submetidas a níveis de potencial osmótico em cloreto de sódio $(\mathrm{NaCl})$ e cloreto de potássio $(\mathrm{KCl})$. Januária, MG, 2018.

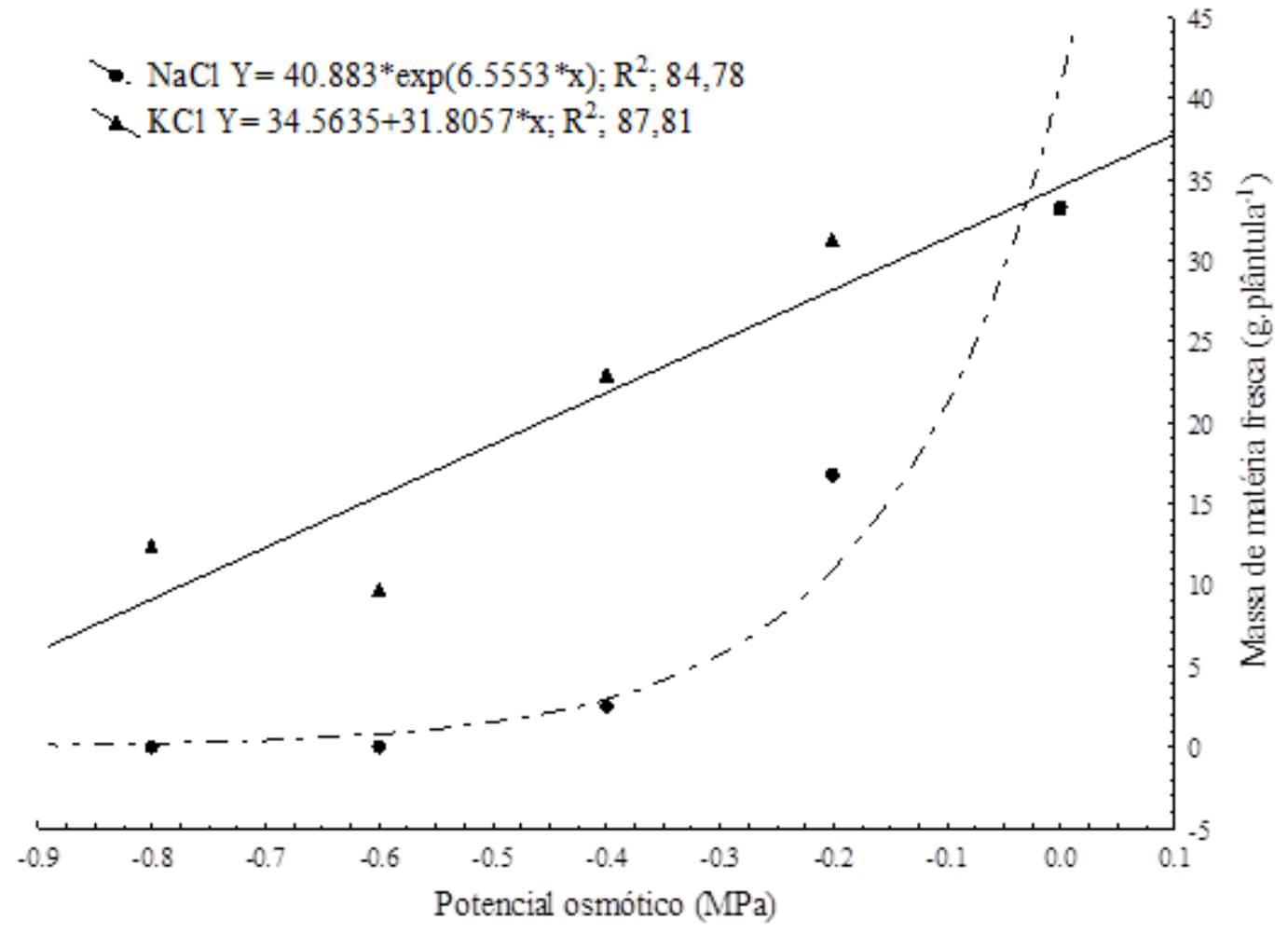

Quando em concentrações mais elevadas, o estresse salino provoca redução no crescimento das plântulas, este fator está atribuído à restrição hídrica que se dá devido à menor velocidade dos processos fisiológicos e bioquímicos ou pela dificuldade de hidrólise e mobilização das reservas da semente (NUNES et al., 2016). Contudo, Lacerda et al. (2006), trabalhando com feijão-caupi, relataram que a redução no comprimento e acúmulo de massa seca da parte aérea e raiz, está associada aos efeitos osmóticos, tóxicos e nutricionais decorrentes do acúmulo de sais na zona radicular da plântula.

Taiz e Zaiger (2013), explicam que em potenciais mais negativos, há uma diminuição de potencial de turgor adequado, acarretando também, menor eficiência nos processos fisiológicos e bioquímicos responsáveis pela expansão celular, apresentando assim, menor peso da biomassa úmida. 
Figura 6. Massa de matéria seca de plântulas de feijão-caupi, Cv. BRS-Pajeú, submetidas a níveis de potencial osmótico em cloreto de sódio $(\mathrm{NaCl})$ e cloreto de potássio $(\mathrm{KCl})$. Januária, $\mathrm{MG}, 2018$.

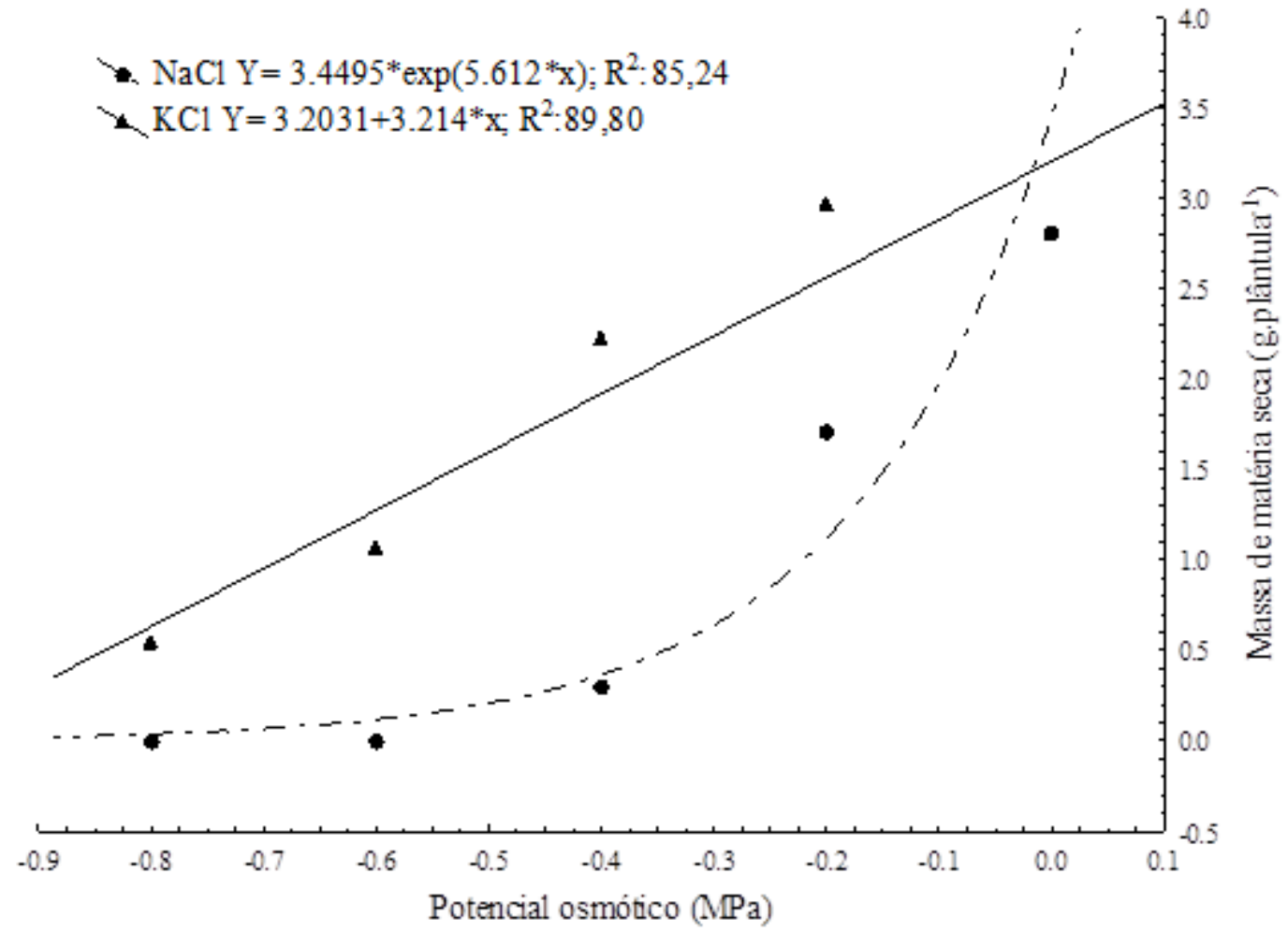

Os mecanismos para tolerância ao sal são complexos e dependem de alterações anatômicas e fisiológicas que ocorrem na planta inteira e não em uma única célula, como o feijão-caupi é uma cultura extensamente cultivada no Nordeste do Brasil, tanto sob condições de irrigação como de lavoura seca, é considerada moderadamente tolerante ao sal, embora, os mecanismos fisiológicos responsáveis por sua tolerância ou sensibilidade não são completamente compreendidos (SOUSA et al., 2003). Os mesmos autores relatam que foram observadas em algumas mudas de feijão-caupi cultivadas sob estresse salino um atraso na germinação e no estabelecimento de plântulas como resultado deste estresse.

Na Figura 7 observa-se o percentual (\%) de germinação, que se ajustou em uma regressão linear de primeiro grau nas sementes submetidas à solução contendo $\mathrm{NaCl}$, apresentando $98,35 \%$ o ponto de máxima germinação calculado em 0,00 $\mathrm{MPa}$ (testemunha). A partir disso, a germinação reduziu $87,87 \%$ quando as sementes foram submetidas ao potencial $-0,20 \mathrm{MPa}$, essa redução expressa $10,48 \%$ quando comparado a testemunha. Para as sementes submetidas ao potencial $-0,4 \mathrm{MPa}$, a germinação das sementes foi de $77,37 \%$. Segundo a análise de regressão, em potenciais inferiores à $-1,8 \mathrm{MPa}$ a germinação torna-se nula. Diante dos resultados expostos as sementes de feijão-caupi cv. BRS Pajeú submetidas à solução de $\mathrm{NaCl}$ com potenciais inferiores à $-0,35 \mathrm{MPa}$, apresentarão uma porcentagem de germinação inferior a $80 \%$. 
Figura 7. Germinação de sementes de feijão-caupi, cv. BRS-Pajeú, submetidas a níveis de potencial osmótico em cloreto de sódio ( $\mathrm{NaCl}$ ) e cloreto de potássio (KCl). Januária, MG, 2018.

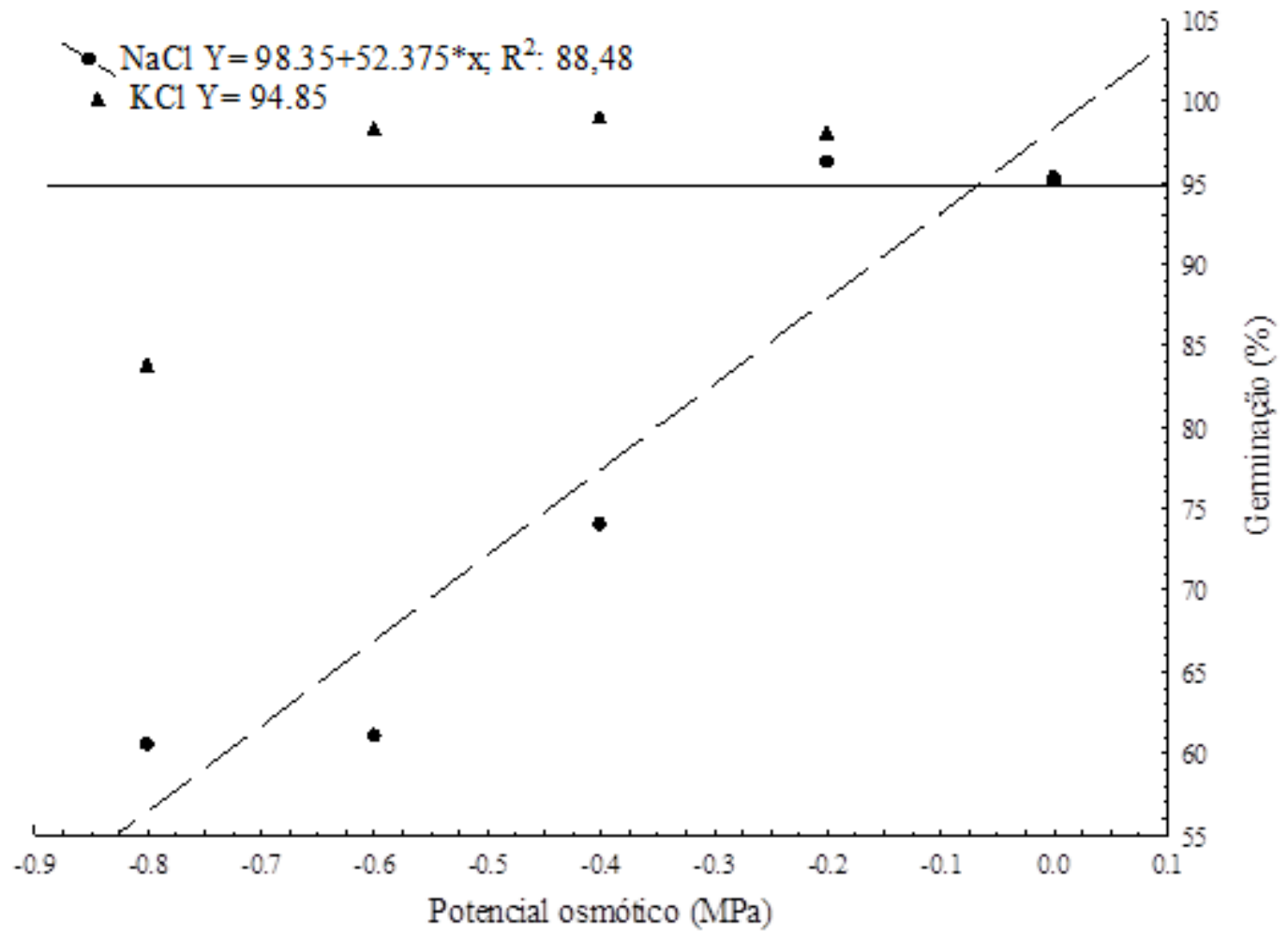

Resultados semelhantes foram encontrados por Coelho et al. (2017), avaliando sementes de diferentes variedades de feijão caupi, evidenciou que o percentual de germinação das sementes para todas as variedades foi próximo de $100 \%$ para o potencial $0,00 \mathrm{MPa}$, tendo um decréscimo gradual à medida que a concentração da solução salina aumentou. Chagas et al. (2018) também concluíram que o aumento da salinidade diminuiu a percentagem de emergência das plântulas de feijão caupi e, que conforme aumenta-se às concentrações a velocidade de germinação reduziu. Como pode-se observar na Figura 7, para sementes submetidas a solução com $\mathrm{KCl}$ nenhum modelo estatístico testado se ajustou para a porcentagem de germinação $x$ potencial osmótico no presente estudo, mantendo-se uma média de $94,85 \%$ de germinação.

Neste estudo, observa-se que existem níveis de potencial osmótico que provocam redução no desempenho das sementes, tornando-se críticos para o desenvolvimento das plântulas. Os resultados revelam a importância da avaliação dos potenciais hídricos do substrato, considerados críticos para a germinação das sementes e estabelecimento das plântulas de feijão-caupi cv. BRS Pajéu.

\section{Conclusão}

As condições de estresse salino prejudicam a germinação e o vigor das sementes de feijãocaupi cv. BRS Pajeú.

A diminuição do potencial osmótico das soluções, reduz o desenvolvimento e o ganho de massa fresca e seca das plântulas de feijão-caupi cv. BRS Pajeú, independente da substância utilizada para indução do estresse.

O cloreto de sódio $(\mathrm{NaCl})$ promoveu efeitos mais drásticos sobre o crescimento das plântulas, quando comparado ao cloreto de potássio $(\mathrm{KCl})$.

As sementes de feijão-caupi cv. BRS Pajeú submetidas a solução de $\mathrm{NaCl}$ com potenciais inferiores à $-0,35 \mathrm{MPa}$, apresenta uma porcentagem de germinação inferior a $80 \%$.

\section{Referências}

ALMEIDA, W.S. et al. Identificação de genótipos de feijão-caupi tolerantes a salinidade, avaliado por meio de método multivariado. Ciência Rural, Santa Maria, v.41, n.11, 2011. https://doi.org/10.1590/S0103$\underline{84782011001100006}$ 
BASTOS, E.A. A cultura do feijão-caupi no Brasil. In: SILVA, K.J.D.; Rocha, M.M.; MENEZES JÚNIOR, J.A.N. Socioeconomia. Teresina: Embrapa MeioNorte, 2016. p. 6-12.

BEWLEY, J.D.; BLACK, M. Seeds: physiology of development and germination. 2. ed. New York: Plenum, 1994. https://doi.org/10.1007/978-14899-1002-8 9

BRAGA, L.F. et al. Efeito da disponibilidade hídrica do substrato na qualidade fisiológica de sementes de feijão. Revista Brasileira de Sementes, Brasília, v.21, n.2, p.95-102, 1999. https://doi.org/10.17801/0101-

3122/rbs.v21n2p95-102

BRASIL. Regras para análises de sementes. Ministério da Agricultura, Pecuária e Abastecimento. Secretária de Defesa Agropecuária - Brasília: MAPA/ACS, 2009.

CARVALHO, N.M.; NAKAGAWA, J. Sementes: ciência, tecnologia e produção. 5. ed. Jaboticabal: FUNEP, 2012.

CHAGAS, C.T.G.; OLIVEIRA, K.S.S.; BARBOSA, J.B.; SILVA, F.P.; DANTAS, T.O.; QUADROS, B.R. Sementes de feijão-caupi (Vigna unguiculata (L.) Walp) submetidas a estresse salino. Revista Cultivando o Saber, v. 11, n.3, p. 258-265, 2018.

COELHO, D.S.; SILVA, J.A.B.; NASCIMENTO, R.L.; COSTA, J.D.S.; SEABRA, T.X. Germinação e crescimento inicial de variedades de feijão caupi submetidas a diferentes concentrações salinas. Revista Verde de Agroecologia e Desenvolvimento Sustentável, v.12, n.2, p.261266, 2017.2 DOI: http://dx.doi.org/10.18378/rvads.v12i2.4419

COELHO, J.B.M.; BARROS, M.F.C.; NETO, E.B.; CORREA, M.M. Comportamento hídrico e crescimento do feijão vigna cultivado em solos salinizados. Revista Brasileira de Engenharia Agrícola e Ambiental, v.17, n.4, p.379-385, 2013. https://doi.org/10.1590/S141543662013000400004

CONAB. Acompanhamento da safra brasileira de grãos, v. 6 - SAFRA 2018/19 - n. 8 - Oitavo levantamento. Maio, 2019.
CRUZ, C.D. Genes Software - extended and integrated with the R, Matlab and Selegen. Acta Scientiarum. v.38, n.4, p.547-552, 2016. DOI: 10.4025/actasciagron.v38i4.32629

DAL'MASO, E.G.; CASARIN, J.; COSTA, P.F.; CAVALHEIRO, D.B.; SANTOS, B.S.; GUIMARÃES, V.F. Salinidade na germinação e desenvolvimento inicial de sementes de chia. Revista Cultivando o Saber, Cascavel, v.6, n.3, p.26-39, 2013.

DALCHIAVON, F.C.; NEVES, G.; HAGA, K.L. Efeito de stresse salino em sementes de Phaseolus vulgaris. Revista de Ciências Agrárias. v.39, n.3, p.404-412, 2016. https://doi.org/10.19084/RCA15161

DEMONTIÊZO, F.L.L.; ARAGÃO, M.F.; VALNIR JUNIOR, M.; MOREIRA, F.J.C.; PAIVA, P.V.V.; LIMA, S.C.R.V. Emergência e crescimento inicial de tomate 'Santa Clara' em função da salinidade e condições de preparo das sementes. Irriga, v.1, p.81-92, 2016. https://doi.org/10.15809/irriga.2016v1n1p81-92

DICKMANN, L.; CARVALHO, M.A.C.; BRAGA, L.F.; SOUSA, M.P. Comportamento de sementes de girassol (Heliantus annuus L.) submetidas a estresse salino. Revista de Ciências AgroAmbientais, v.3, p.64-75, 2005.

FREIRE, M.H.D.C.; SOUSA, G.G.D.; DE SOUZA, M.V.; CEITA, E.D.; FIUSA, J.N.; LEITE, K.N. Emergence and biomass accumulation in seedlings of rice cultivars irrigated with saline water. Revista Brasileira de Engenharia Agrícola e Ambiental, v.22, n.7, p.471-475, 2018. DOI: http://dx.doi.org/10.1590/18071929/agriambi.v22n7p471-475

LACERDA, C.F.; ASSIS, J.O.; FILHO, L.C.A.; OLIVEIRA, T.S.; GUIMARÃES, F.V.A.; GOMESFILHO, E.; PRISCO, J.T.; BEZERRA, M.A. Morphophysiological responses of cowpea leaves to salt stress. Brazilian Journal of Plant Physiology, Londrina, v.18, n.4, 2006. https://doi.org/10.1590/S1677$\underline{04202006000400003}$

LARRÉ, C.F.; MARINI, P.; MORAES, C.L.; AMARANTE, L.; MORAES, D.M. Influência do 24epibrassinolídeo na tolerância ao estresse salino em plântulas de arroz. Semina: Ciências Agrárias, 
v.35, p.67-76, 2014. DOI: 10.5433/1679$\underline{0359.2014 v 35 n 1 p 67}$

MARCOS FILHO, J. Fisiologia de sementes de plantas cultivadas. 1. ed. Piracicaba: FEALQ, 2005.

MOTERLE, L. M. et al. Germinação de sementes e crescimento de plântulas de cultivares de milhopipoca submetidas as estresse hídrico e salino. Revista Brasileira de Sementes, v.28, p.169-176, 2006. https://doi.org/10.1590/S0101$\underline{31222006000300024}$

NUNES, R.T.C.; NETO, A.C.A.; SOUZA, U.O.; MORAIS, O.M.; Desempenho germinativo de sementes de girassol submetidas ao estresse salino. Cultura Agronômica, Ilha Solteira, v.25, n.1, p.79-92, 2016.

PAIVA, T.S.S. Tolerância à salinidade em cultivares de feijão-caupi. 2014. Dissertação (Mestrado em Agronomia) - Universidade Estadual do Sudoeste da Bahia, Vitória da Conquista, 2014.

PEREIRA, M.R.R.; MARTINS, C.C.; SOUZA. G.S.F.; MARTINS, D. Influência do estresse hídrico e salino na germinação de Urochloa decumbens e Urochloa ruziziensis. Bioscience Journal, v.28, n.4, p.537-545, 2012.

RABANI, A.R.C.; SILVA-MANN, R.; FERREIRA, R.A.; CARVALHO, S.V.A.; NUNES, F.B.S.; BRITO, A.S. Efeito do estresse salino sobre atributos da germinação de sementes de girassol. Scientia plena, v.9, n.5, p.12-23, 2013.

RIBEIRO, M.C.C.; MARQUES, B.M.; AMARRO FILHO, J. Efeito da salinidade na germinação de sementes de quatro cultivares de girassol (Helianthus annuus L.). Revista Brasileira de Sementes, v.23, n.1, p.281-284, 2001. https://doi.org/10.17801/0101-

3122/rbs.v23n1p281-284

RIBEIRO, M.R.; RIBEIRO FILHO, M.R.; JACOMINE, P.K.T. Origem e classificação dos solos afetados por sais. In: Gheyi, H. R.; Dias, N.S.; Lacerda, C. F. de; Gomes Filho, E. (ed.). Manejo da salinidade na agricultura: estudos básicos e aplicados. Fortaleza: INCT Sal, 2016. p. 9-15.

SANTOS, P.R.; RUIZ, H.A.; NEVES, J.C.L.; ALMEIDA, E.F.; FREIRE, M.B.G. Germinação, vigor e crescimento de cultivares de feijoeiro em soluções salinas. Revista Brasileira de Engenharia Agrícola e Ambiental v.13, (Supl.), p.882-889, $2009 . \quad$ https://doi.org/10.1590/S1415$\underline{43662009000700010}$

SILVEIRA, J.A.G.; ARAÚJO, S.A.M.; LIMA, J.P.M.S.; VIÉGAS, R.A. Roots and leaves display contrasting osmotic adjustment mechanisms in response to $\mathrm{NaCl}$-salinity in Atriplex numularia. Environmental and Experimental Botany, v.66, p.1-8, 2009. https://doi.org/10.1016/i.envexpbot.2008.12.015

SOUSA, M.A.; SILVA, D.C.; SIMON, G.A. Desempenho de plântulas de melancia submetidas a diferentes níveis de potencial osmótico. Global Science and Tecnology. v.3, n.2, p.08 - 19, 2009.

SOUSA, M.F.; CAMPOS, F.A.P.; PRISCO, J.T.; ENÉAS-FILHO. J.; GOMES FILHO, E. Growth and protein pattern in cowpea seedlings subjected to salinity. Biologia Plantarum. v.47, n.3, p.341-346, 2003.

DOI: 10.1023/B:BIOP.0000023875.63226.67

SOUZA, R.P.; MACHADO, E.C.; SILVEIRA, J.A.G.; RIBEIRO, R.V. Fotossíntese e acúmulo de solutos em feijoeiro caupi submetido à salinidade. Pesquisa Agropecuária Brasileira, v.46, n.6, p.586-592, 2011. https://doi.org/10.1590/S0100$\underline{204 \times 2011000600003}$

SOUZA, T.M.A.; SOUZA, T.A.; SOLTO, L.S.; SÁ, F.V.S.; PAIVA, E.P.; BRITO, M.E.B.; MESQUITA, E.F. Crescimento e trocas gasosas do feijão caupi cv. BRS pujante sob níveis de água disponível no solo e cobertura morta. Irriga, Botucatu, v.21, n.4, p.796-805, 2016. DOI: https://doi.org/10.15809/irriga.2016v21n4

TAIZ, L.; ZEIGER, E. Fisiologia Vegetal. 5. ed. Porto Alegre: Artmed, 2013.

TAIZ, L.; ZEIGER, E.; MØLLER, I. .; MURPHY, A. Fisiologia e desenvolvimento vegetal. 6. ed. Porto Alegre: Artmed, 2017.

VALE, J.C.; BERTINI, C.; BORÉM, A. Feijão-caupi do plantio à colheita. Viçosa: Ed.UFV, 2017. 
VIEIRA, R.D.; CARVALHO, N.M. Testes de vigor em sementes. Jaboticabal: FUNEP, 1994. 